\title{
Simulated Case Studies Illustrate Interprofessional Education for Alcohol and Drug Use Screening for Healthcare Professionals
}

\author{
Kathy Puskar, DrPH, RN, FAAN
}

Professor and Associate Dean for Undergraduate Education, University of Pittsburgh School of Nursing, 3500 Victoria Street, 350 Victoria Building, Pittsburgh, PA. krp12@pitt.edu

\section{Ann M. Mitchell, PhD, RN, FAAN}

Professor of Nursing, University of Pittsburgh School of Nursing, Health \& Community Systems 3500 Victoria Street, 415 Victoria Building, Pittsburgh, PA ammi@pitt.edu

\section{Heeyoung Lee, PhD, PMHNP-BC}

Assistant Professor, University of Pittsburgh School of Nursing, Health \& Community Systems 3500 Victoria Street, 415 Victoria Building, Pittsburgh, PA.

$$
\text { leehee@pitt.edu }
$$

\section{Irene Kane, PhD, MSN, RN, CNAA, EP-C}

Associate Professor, University of Pittsburgh School of Nursing, Health \& Community Systems 3500 Victoria Street, 415 Victoria Building, Pittsburgh, PA.

$$
\text { irk1@pitt.edu }
$$

\section{Susan A. Albrecht, PhD, RN, CRNP, FAAN}

Associate Professor \& Associate Dean for Special Prijects, University of Pittsburgh School of Nursing, 3500 Victoria Street, 350 Victoria Building, Pittsburgh, PA. saa01@pitt.edu

\section{Linda R. Frank, PhD, MSN, ACRN, FAAN}

Associate Professor of Public Health, Medicine, \& Nursing, Infectious Diseases and Microbiology University of Pittsburgh Graduate School of Public Health,

130 De Soto Street, A427 Crabtree Hall, Pittsburgh, PA.

$$
\text { frankie@pitt.edu }
$$

\section{Holly Hagle, PhD}

Director of the National SBIRT ATTC at IRETA, Institute for Research,

Education, and Training in Addictions (IRETA), 611 William Penn Place, Suite 403, Pittsburgh, PA. holly@ireta.org

\section{Dawn Lindsay, PhD}

Director of Evaluation Services, Institute for Research,

Education, and Training in Addictions (IRETA), 611 William Penn Place, Suite 403, Pittsburgh, PA. dawn@ireta.org

\section{Marie Fioravanti, DNP, RN}

Assistant Professor, University of Pittsburgh School of Nursing, Acute \& Tertiary Care 3500 Victoria Street, 327 Victoria Building, Pittsburgh, PA.

$$
\text { maf80@pitt.edu }
$$




\begin{abstract}
Online Interprofessional Education (IPE) facilitates training and education of healthcare professionals in rural settings to better address the needs of their patients with substance use problems. The paper 1) describes the use of two online simulated case studies, illustrating IPE of Screening, Brief Intervention, and Referral to Treatment (SBIRT); 2) explores the effect of the online IPE on the competency level of 161 healthcare professionals, related to addressing their patients' substance use through interprofessional collaborative practices; and 3) discusses the implications of using simulated case studies to practice the interprofessional use of SBIRT. The study demonstrates a replicable model to provide healthcare professionals with opportunities for effective IPE.
\end{abstract}

Keywords: alcohol and other drug use; SBIRT; screening; nursing; public health; behavioral health;interprofessional collaborative practice;interprofessional education

\title{
1. BACKGROUND
}

Incorporating simulated case studies into not only interprofessional education (IPE), but also the practice of Screening, Brief Intervention, and Referral to Treatment (SBIRT) is a way to accommodate the needs of busy healthcare professionals - particularly in online settings-in enhancing the delivery of coordinated, timely, and quality care for substance use problems. Many healthcare professionals have been involved in IPE through graduate training and professional role courses [1]. However, IPE approaches often are not utilized in rural settings due to fewer staff, IPE role models, and limited access to educational opportunities. As an evidence-based universal screening tool, SBIRT and, in particular, alcohol screening and brief intervention (SBI), is recommended by the U.S. Preventive Services Task Force to be included in every health assessment [2]. Furthermore, studies [3] have demonstrated that patients readily accept SBIRT as part of their medical care.

Combining IPE and SBIRT in an online simulation venue is an interactive approach to: 1) present, model, and reinforce best practices among practicing healthcare providers; 2) increase competencies in IPE and SBIRT to improve health outcomes and coordinate care; 3) promote clinical innovation through improved knowledge, skills, and attitudes; and 4) reduce the time and costs of providing services. The project reported in this article provided an opportunity for nurses and behavioral health professionals to learn about IPE and SBIRT. Moreover, the use of online simulated case studies featured in the project supports the goals of healthcare integration [4] by facilitating health and behavioral health clinicians' learning about substance use screening and the importance of collaboration, sharing, and cooperation among disciplines in the work setting to improve patient care.

\section{IPE and the Use of Simulated Case Studies}

The literature $[5,6,7,1]$ reports many advantages of IPE, such as the ability to provide support to patients with chronic conditions. Many leading policy organizations, such as the Institute of Medicine [IOM] recognize several factors that influence the success of health and behavioral health professionals collaborating in multiple healthcare settings. The IOM [6] has identified three factor focus areas that determine the success of interprofessional collaboration: 1) roles and responsibilities; 2) respect, trust, and communication; and 3) hierarchy and education. Moreover, recent studies of nursing communication have identified that nurses and general practitioners often face difficulty defining roles and communicating effectively in the general (family) practice [8].

Simulated case studies and interprofessional team learning are effective tools in improving the common themes of communication and teamwork between health and behavioral health professionals - specifically when caring for patients with chronic conditions. One example of this is the evaluation of a simulation-based interprofessional education (Sim-IPE) program using TeamSTEPPS (i.e., team strategies and tools to enhance performance and patient safety) to incorporate simulation scenarios of deteriorating patients. According to Liaw, Zhou, Lau, Siao, and Chan [9], upon completion of a Sim-IPE program, medicine and nursing groups showed significant improvement in self-confidence and perception when working with other healthcare workers as a team. Additionally, the Sim-IPE program was effective in improving collaborative skills (i.e., teamwork) for students in medicine and nursing, resulting in better care for patients with deteriorating health [9].

Due to the increase in chronic health conditions worldwide, the demand for interprofessional healthcare teams that can facilitate improved patient outcomes is greater than ever before. For 
example, Nadan and Scott [10] describe a holistic approach to IPE including social, psychological, biological, environmental, and economic factors to consider when collaborating regarding patient care. Simultaneously, Supper, Catala, Lustman, Chemla, Bourgueil, and Letrilliart [11] conducted a systematic review that assessed the positive and negative factors in the primary health field that contributes to promoting interprofessional collaboration. The results of this systematic review, which were generated using thematic analysis, revealed that the success of interprofessional collaboration in primary care depended on those who valued collaboration, sought to improve quality of care, and welcomed new professional fields [11]. Both Nadan and Scott [10] and Supper et al. [11] demonstrate that an emphasis on interprofessional collaboration plays a key role in the success that organizations experience in training both health and behavioral health professionals to include patients and their caregivers as active team members in the healthcare management of their patients.

Hanyok, Walton-Moss, Tanner, Stewart, and Becker [12] describe the effects that long-term IPE training on adult nurse practitioner students and internal medicine resident physicians. In this study, each group was educated on the professional roles of their co-group and the importance of team collaboration and conflict resolution prior to working together [12]. Hanyok, Walton-Moss, Tanner, Stewart, and Becker [12] report that pre-training results enhanced interprofessional collaboration among the participants; however, the participants did not believe that IPE had an effect on their communication skills or patient outcomes.

In a comparison between undergraduate students and alumni (postgraduate students exposed to patients), Makino, Shinozaki, Hayashi, Lee, Matsui, Kururi, and Watanabe [13] report that effective IPE resulted in not only superior patient care, but also a pronounced level of improved patient satisfaction. Attitudes of a group of alumni trained in IPE at the pre-licensure stage and postgraduate stage were examined [13]. Continuing education (CE) is also now embracing IPE to form a wellrounded curriculum focused on improved patient outcomes [14].

The provision of IPE is important for the development of nurses and all health and behavioral healthcare workers because this provision promotes improved patient outcomes. However, sufficient opportunities to learn IPE often are not made available for health professionals to take knowledge forward in their careers. For example, Bennett, Gum, Lindeman, Lawn, McAllister, Richards, and Ward [15] surveyed 33 faculty members at a health facility in Australia to determine their understanding of IPE and results indicated that faculty unanimously supported the IPE approach, but identified leadership support, curriculum, costs, and funding as barriers to the IPE success [15].

There are several challenges that professionals encounter when incorporating IPE in their contexts of practice (e.g., time, costs, and administrative support). Because each health professional has already developed and adopted discipline-specific roles, young health professionals can find it a challenge to work together effectively. This focus on discipline-specific roles makes it difficult for IPE programs to engage and motivate health professionals to go beyond perceived borders to collaborate interprofessionally [16]. Therefore, reinforcing the concept of IPE among practicing health and behavioral healthcare professionals must be integrated into clinical practice and education. To accomplish this, the creative use of technology shows promise. For example, we hypothesized that providing a user friendly, online format geared to the employed health professional of any discipline, combined with an IPE case study approach, would promote interaction and discussion among health professionals, which can help build collaborative, interprofessional teams to improve specific patient care health outcomes.

\section{METHOD}

This project utilized a simulated case study methods to implement SBIRT within interprofessional collaborative practice (IPCP). Gaba's [17] simulation approach to strengthen skills and experiences that evoke or replicate a substantial aspect of real work in a fully interactive manner served as the guiding definition for the SBIRT case studies that we used. This simulated case study method has been used for professional and academic training purposes in prior studies [18].

\section{Designing Simulated Case Studies to Reinforce IPCP}

For the project, two cases describing patients with substance use and comorbid medical conditions were first developed, reviewed, and refined by health professionals comprising nursing faculty, nurse 
practitioners, and Institute for Research, Education and Training in Addictions (IRETA) specialists. Second, case study simulation scripts were written to depict health professionals (i.e., nurse, physician, and social worker) collaborating to treat patients in particular clinical situations. Third, actors were recruited to play the roles in the case study simulations, and then each of the simulations was video recorded in the Educational Technology and Innovation facility at the University of Pittsburgh, School of Nursing. Fourth, the video recordings of the case studies simulations were made emphasizing the following questions: 1) Who is the team? 2) How does the team go about their work? 3) What does the team achieve? 4) What are the patient outcomes? 5) What is the level of patient satisfaction with the team's practice?

During each case study, the four competency domains issued by the Interprofessional Education Collaborative Expert Panel (IECEP) in May 2011 [1] for IPE were applied: Domain 1: Values and Ethics for Interprofessional Practice; Domain 2: Roles and Responsibilities; Domain 3: Interprofessional Communication; and Domain 4: Teams and Teamwork [1].

The protocol used to develop, present, and discuss the simulated IPE case studies was based on the standards of simulation disseminated by the International Nursing Association for Clinical Simulation and Learning (INACSL) [19]. Themes emphasized in our simulation protocol comprised script preparation, enactment, debriefing, and supervisor/student review. The seven standards of clinical simulation that we adapted from INACSL [19] to inform our protocol are the following:

1. Standard I: Terminology—Provide Consistency

2. Standard II: Professional Integrity of Participant

3. Standard III: Participant Objectives - Clear and Measurable

4. Standard IV: Facilitation-Multiple Methods

5. Standard V: Facilitator-Proficiency

6. Standard VI: Debriefing Process-Improve Practice through Reflection

7. Standard VII: Participant Assessment and Evaluation

These standards underscore that simulation is a technique — not a technology — to amplify experiences that evoke or replicate substantial aspects of the real world clinical experience in a fully interactive manner [17].

By reviewing simulation cases, we created a link between analysis in the IPE with the SBIRT focus for interprofessional collaborative discussion to improve the patient's health outcomes. Through our method of presenting simulation cases, participants were able to integrate concepts of IPE and SBIRT to improve knowledge and skills for day-to-day interprofessional collaboration in their work environment. In the IPE simulation cases, SBIRT was integrated into an evidence-based process to demonstrate and document the effect on clinical outcomes. Two of our simulation cases featured IPE and SBIRT concepts that exemplified Ellet's [20] assertion that "collaboration is what the case method is about" (p. 91) as IPE faculty and participating health professionals actively discussed the patient issues raised in the simulation cases and collaborated to reach an effective conclusion regarding quality improvement for patient care (see Figure 1).

Figure 1. Case Study 1

David is a 35-year-old Caucasian male who goes to the emergency room because his wife could not wake him from sleeping that morning. He reports suffering from pain due to diagnosed fibromyalgia. He also suffers insomnia, anxiety, and loss of interest in activities. To help deal with his pain and lack of sleep, he has been drinking two to three glasses of wine in the evening and taking pain and sleep medications.

After triage, David was seen in the emergency department by Susan, Certified Registered Nurse Practitioner (CRNP). David's chief complaint was back pain. The healthcare team used the Drug Abuse Screening Test (DAST) [21] and the Alcohol Use Disorders Identification Test (AUDIT) [22] screens and noted that David was using prescription medicine based on his level of pain (not as prescribed) as well as drinking alcohol. Dr. Brown, MD communicated with a social worker to set up a consultation for David to be seen in the pain clinic for relief of back pain.

Prior to discharge, Dr. Brown calls David's primary care physician (PCP) to discuss David's 
assessment, treatment, evaluation, and referral. His newly assigned social worker makes an appointment for David and his wife to be seen at the Behavioral Health Clinic for counseling and further assessment based on the results of the DAST and AUDIT. At discharge, the CRNP, who uses motivational interviewing techniques, discusses with David how to understand the current stress that he is experiencing with pain and his new diagnosis of fibromyalgia. The CRNP presents patient education on the dangers of using alcohol with prescription medication and encourages David and his wife by explaining that the healthcare team will follow through with supporting David to manage his pain-especially involvement with the pain management clinic, the social work services - in conjunction with his PCP's office.

Six professionals are involved in David's care: a CRNP, Dr. Brown, a social worker, his PCP, a pain clinic therapist, and a Certified Addiction Counselor. Evidence-based practice (i.e., SBIRTScreening, Brief Intervention, and Referral to Treatment) plus Interprofessional Education (IPE) was emphasized so that the interprofessional team could provide holistic care. IPE builds the IPCP connection using SBIRT as the link to engage a collaborative relationship for patient-centered care. Therefore, understanding the contributing factors of David's situation is of primary importance so that the team can offer person-centered care.

Our simulated case studies also reinforced the World Health Organization's (WHO) [23] IPE description of an experience that "occurs when students from two or more professions learn about, from, and with each other" (p. 7). This type of collaborative practice can occur when health professionals from different backgrounds are able to work together with patients, families, and communities to deliver a higher quality of health care [23].

Our simulation case scripts conveyed the IPE goals as the project's healthcare professionals observed four actors (patient, nurse, doctor, social worker) working together to complete the SBIRT process. Live sessions were filmed in the Video Production Room of the Education Technology Innovation (ETI) Center in the School of Nursing and edited for content and technical issues resulting in the final version of two cases (see Figure 1 and Figure 2). The faculty conducting the IPCP webinar conveyed appreciation for participant's enrollment, allotted time for participant introductions, reviewed IPCP content domains, reviewed substance use epidemiology reinforcing the need to conduct SBIRT routinely, and introduced the case as a discussion instrument for IPE. Faculty engaged participants so that IPE learning was comfortable, interactive, and involved recognizing the value of IPCP in action. Incentives in the form of gift cards were utilized to encourage participants to complete the project. Continuing education units (CEUs), totaling $132 \mathrm{CEUs,} \mathrm{were} \mathrm{also} \mathrm{provided} \mathrm{for} \mathrm{both} \mathrm{nurses} \mathrm{and}$ behavioral health providers.

Figure 2. Case Study 2

A 55 year-old Chinese businessman is brought into the hospital because he was hit by a car while crossing the street in ongoing traffic. Witnesses say that he appeared impaired. At the hospital, he says that this is his first instance receiving Western medical care and in the past has relied upon Chinese medicine. He is diagnosed with three broken ribs and untreated diabetes mellitus. He receives insulin and pain medication, but insists on being discharged, opting not to receive a crash course on diabetes management. A home health nurse is ordered to visit him the next day and, upon arriving, notices a strong smell of alcohol on the man's breath.

The nurse performs a blood glucose test, which is 400 . He also appears to be slurring his words. When asked if he had been drinking, he replies that he has, in order to help with the pain. The nurse begins SBIRT with the patient and discovers that he has been drinking shots of whiskey to help relieve the pain of his broken rib and to help with his insomnia and then calls upon the MD and SW to review the case for assessment completion with further planning to include the patient.

Moreover, our simulation case scripts-and discussion about them during the training sessionhighlight the IOM reports on IPE. The IOM [24] Measuring the Impact of Interprofessional Education on Collaborative Practice and Patient Outcomes describes methods needed to measure the impact of IPE on not only collaborative practice, but also health and system outcomes. In particular, the report highlights four areas that, if addressed, would provide a strong foundation for evaluating the impact of IPE on collaborative practice and patient outcomes: 1) more closely aligning the education and healthcare delivery systems, 2) developing a framework for measuring the impact of IPE, 3) 
strengthening the evidence base for IPE, and 4) more effectively linking IPE with changes in collaborative behavior [24]. The conceptual model for evaluating IPE, adaptable to particular settings in which it is applied, provided evaluative guidelines for measuring the impact of this project [24]. In addition, the National Center for Interprofessional Practice and Education (NCIPE) launched a webbased collection of 26 existing IECEP measurement instruments that also served as references for evaluation [25].

\section{Sample}

Participants consisted of 161 healthcare professionals who completed the online case simulations. The average age of the participants was 32.5 years $(\mathrm{SD}=13.89)$, and the majority of participants were female $(n=137 ; 85.1 \%)$. The professionals were grouped into three categories: nurses (i.e., RNs, advanced practice, and student nurses) $(\mathrm{n}=82 ; 51 \%)$, behavioral health counselors (i.e., social workers, counselors, and substance abuse professionals $)(n=53 ; 33 \%)$, and public health professionals (i.e., public health workers and health educators) $(n=26 ; 16 \%)$.

\section{Measures}

Data from an Evaluation Checklist via online survey were collected regarding participants' behaviors with respect to SBIRT and IPCP. The 14-item Evaluation Checklist, developed by the project team, consists of 12 items that assess interprofessional behaviors, one item that assesses frequency of interprofessional collaboration, and one item that assesses frequency of utilizing screening and brief interventions.

\section{Analysis}

Our study featured a quasi-experimental approach. Descriptive statistics were used to report demographic data of healthcare professionals participating in the study. Frequencies were used to describe responses on the evaluation checklist. Finally, due to the ordinal nature of the data, a Wilcox singed-rank test was used to determine whether or not responses to the SBIRT and IPCP practice items changed as a result of the simulated case study education.

\section{RESUlts}

Overall, participants reported high rates of IPCP competencies. Table 1 summarizes the frequencies of each response on the Evaluation Checklist. The two behavioral items on the checklist ("How many SBIRT screenings have you conducted to date?" and "How frequently do you use IPCP competencies in your practice?") were analyzed for change in distribution from before to after the IP Dialogue, using the Wilcoxon signed-rank test due to the ordinal nature of the data. The distributions of both the SBIRT screening and IPCP competencies items changed significantly in the expected direction (SBIRT screenings, $\mathrm{Z}=-4.37, \mathrm{p}<0.01$; IPCP competencies, $\mathrm{Z}=-2.62, \mathrm{p}<0.01$ ). Figures 1 and 2 illustrate these results. As shown, participants were less likely to reply "none" or "never" and more likely to report some frequency of these behaviors following the IP Dialogue.

Table 1. Evaluation Checklist Results Following IP Dialogue $(n=161)$

\begin{tabular}{|c|c|c|c|c|c|}
\hline $\begin{array}{l}\text { Rate how likely you would be to ... } \\
\text { during your daily practice. }\end{array}$ & $\begin{array}{r}\text { Very } \\
\text { Unlikely }\end{array}$ & Unlikely & Neutral & Likely & $\begin{array}{r}\text { Very } \\
\text { Likely }\end{array}$ \\
\hline $\begin{array}{l}\text { Collaborate effectively with your } \\
\text { interprofessional team }\end{array}$ & & & $3.7 \%$ & $34.2 \%$ & $62.1 \%$ \\
\hline $\begin{array}{l}\text { Communicate effectively with your } \\
\text { interprofessional team }\end{array}$ & & & $1.9 \%$ & $36.0 \%$ & $62.0 \%$ \\
\hline $\begin{array}{l}\text { Share in decision making with your } \\
\text { interprofessional team }\end{array}$ & & & $4.4 \%$ & $37.1 \%$ & $58.5 \%$ \\
\hline Dialogue with team members & & & $2.5 \%$ & $33.8 \%$ & $63.7 \%$ \\
\hline $\begin{array}{l}\text { Voice knowledge of role of nurse, public } \\
\text { health professional or community health } \\
\text { worker, and behavioral health worker }\end{array}$ & & $0.6 \%$ & $5.0 \%$ & $44.1 \%$ & $50.3 \%$ \\
\hline Problem-solve as a team & & & $3.8 \%$ & $33.8 \%$ & $62.5 \%$ \\
\hline Actively participate in team-based care & & $1.2 \%$ & $5.6 \%$ & $33.5 \%$ & $59.6 \%$ \\
\hline $\begin{array}{l}\text { Voice knowledge of value of nurse, } \\
\text { public health professional or community } \\
\text { health worker, and behavioral health } \\
\text { worker }\end{array}$ & & & $8.1 \%$ & $39.1 \%$ & $52.8 \%$ \\
\hline Engage in interprofessional & & & $3.1 \%$ & $35.4 \%$ & $61.5 \%$ \\
\hline
\end{tabular}


Simulated Case Studies Illustrate Interprofessional Education for Alcohol and Drug Use Screening for Healthcare Professionals

\begin{tabular}{|c|c|c|c|c|c|}
\hline communication & & & & & \\
\hline Demonstrate interprofessional teamwork & & & $2.5 \%$ & $37.7 \%$ & $59.7 \%$ \\
\hline $\begin{array}{l}\text { Aware of intersection of individual and } \\
\text { team responsibility }\end{array}$ & & & $5.0 \%$ & $38.1 \%$ & $56.9 \%$ \\
\hline Conduct SBIRT screenings & $5.0 \%$ & $10.7 \%$ & $15.7 \%$ & $39.6 \%$ & $28.9 \%$ \\
\hline
\end{tabular}

During the IP Dialogues, participants were asked to reflect on their behaviors with respect to SBI and interprofessional collaboration. One hundred percent of the participants agreed with the focus of the IOM IPCP domains. Sixty percent of participants agreed with the statement, "I work as part of an interprofessional collaborative practice (IPCP) team." Ninety one percent of the participants reported that they used IPCP competencies at least once per day.

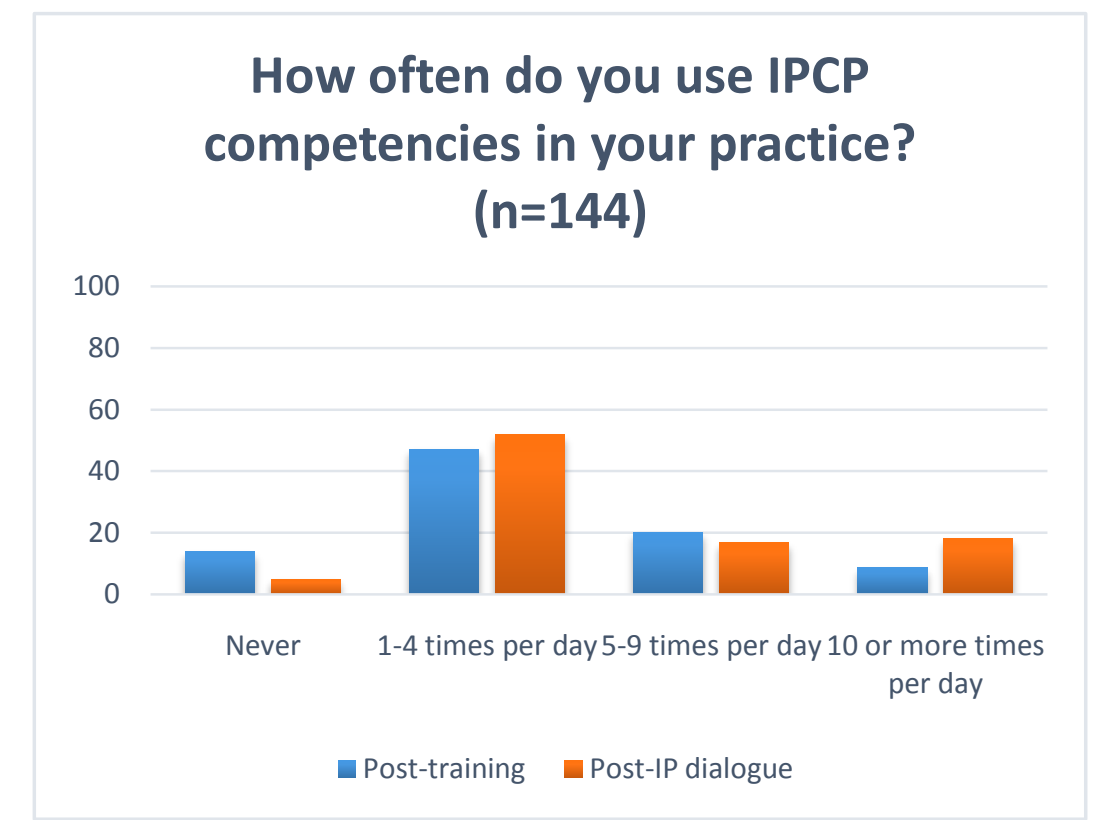

Figure3. Distribution of IPCP competencies item on evaluation checklist.

Sixty percent of the participants reported that they have not yet conducted an SBIRT screening, and only nine percent reported that they do not use IPCP competencies. Only seven participants (i.e., 7\%) agreed with the statement, "I am having a hard time connecting the IPCP domains in my daily work." Concerning SBIRT screenings, 10 participants reported that they have conducted 10 or more SBIRT screenings to date, $6 \%$ have conducted five to nine screenings, and $23 \%$ have conducted one to four screenings. Moreover, 83 participants reported that they have implemented a component of what was learned in their practice from the online IPE program. Evaluative comments were solicited during a live WebEx videoconference in which participants were asked to provide qualitative feedback about the program, and the majority provided comments such as, "It was good to reinforce IPE."

\section{How many SBIRT screenings have you conducted to date? $(n=142)$}

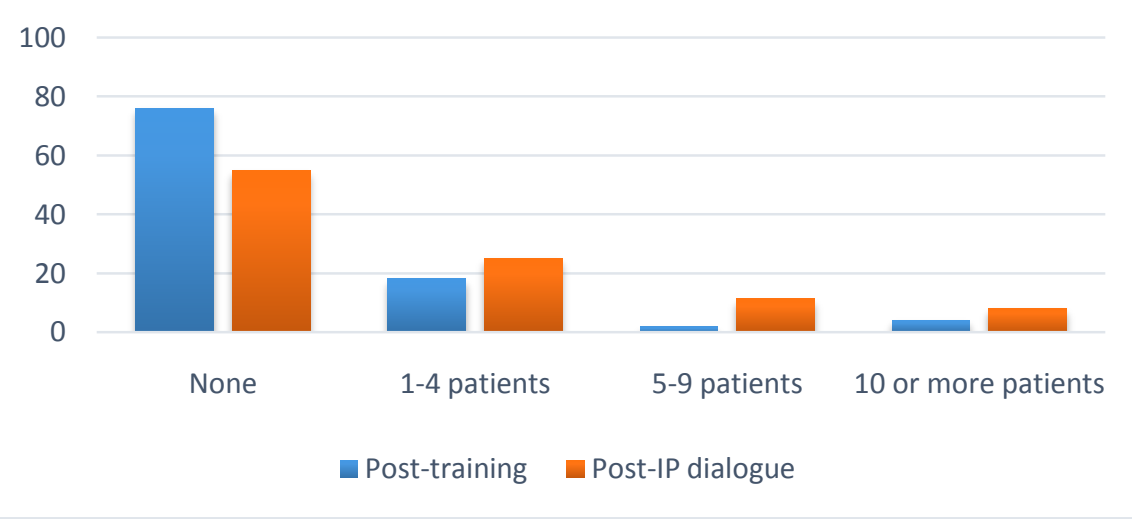

Figure 4. Distribution of SBIRT screening item on evaluation checklist. 


\section{Implications of Using Simulated Case Study to Practice IPE and SBIRT}

Although the integration of IPE through an SBIRT link with an online case simulation required hours of preplanning, editing, and consultation to resolve issues and potential issues related to using the technological platform, our successful results were worth the effort. Using this platform provided advantages for participating health professionals such as 1) the availability of course content after work or during work hours as allowed and 2) the time flexibility of online education. The userfriendly online IPE modules that highlighted SBIRT with case methodology were well received by the participants. The two simulated case studies shown in Figure 1 and Figure 2, in addition to depicting a male displaying alcohol use and fibromyalgia and a pregnant woman screened for alcohol use, emphasize Roethlisberger's approach - the health professionals who participated in the training session reported perceiving the value of an IPE-SBIRT case that promoted IPCP development for better outcomes. As William Ellet [20] states, "In the lecture method, learners receive knowledge from an expert. In the case method, learners make the knowledge with the assistance of an expert" (p. 7). Given that IPE is now required in health science education by Accreditation Standards in schools of pharmacy, medicine, repertory, and nursing, using cases and the user friendly online methodology is a promising method by which to meet these standards.

Not only does the IOM call for the redesign of health delivery and the promotion of interprofessional practice to improve the quality of health outcomes and the satisfaction of patients [1], but the Institute on Healthcare Improvement (IHI) also supports IPE as a framework to optimize health system performance [26]. In fact, the IHI has advanced the three following healthcare system transformation dimensions: 1) improving the patient experience of care (including quality and satisfaction), 2) improving the health of populations, and 3) reducing the per capita cost of health care [26]. This IHI triple aim implies that good, patient-centered care addresses all three aims simultaneously. Considering both the IOM and IHI recommendations, online IPE clearly can be part of the options available to health professionals to efficiently accommodate not only a future of learning, but also an era of positive healthcare transformation outcomes.

A key to IPE success is reinforcing the widespread interest in interprofessional education by policymakers, clinicians, institutions, and educators in recognition of the importance of promoting team-based care. Clearly the use of IPE as an approach to improving care coordination, implementing best practices, utilizing the latest clinical research in treatment, and integrating a biopsychosocial model of intervention can be "transformational" for clinical care, health systems, and the healthcare consumer. The use of online simulated case studies as IPE - in conjunction with SBIRT learningprovides a clear intervention approach to the engagement and implementation of both the IOM and IHI initiatives to enhance IPE. As our data suggests, many practicing health professionals are eager to improve their knowledge and skill in interprofessional practice and this study demonstrates a model for providing a useable, effective, accessible and engaging learning platform through the use of distance-based technology and case-based learning.

\section{ACKNOWLEDGEMENTS}

This project is supported in part by funds from the Division of Nursing (DN), Bureau of Health Professions (BHPr), Health Resources and Services Administration (HRSA), Department of Health and Human Services (DHHS) under cooperative agreement number UD7HP25060. The information or content and conclusions are those of the authors and should not be construed as the official position or policy of, nor should any endorsements be inferred by the DN, BHPr, HRSA, DHHS or the U.S. Government.

\section{Declaration of Interest}

The authors report no declarations of interest.

\section{REFERENCES}

[1] Interprofessional Education Collaborative Expert Panel (IECEP). (2011). Core competencies for interprofessional collaborative practice: Report of an expert panel. Washington, D.C.: Interprofessional Education Collaborative.

[2] Finnell, D. S. (2012). A clarion call for nurse-led SBIRT across the continuum of care. Alcoholism: Clinical and Experimental Research, 36(7), 1134-1138. 
[3] Broyles, L. M., Rosenberger, E., Hanusa, B. H., Kraemer, K. L., \& Gordon, A. J. (2012). Hospitalized patients' acceptability of nurse-delivered Screening, Brief Intervention, and Referral to Treatment. Alcoholism: Clinical and Experimental Research, 36(4), 725-731.

[4] Sacks, S., Gotham, H. J., Johnson, K., Padwa, H., Murphy, D., \& Krom, L. (2015). ATTC white paper: Integrating substance use disorder and health care services in an era of health reform. Addiction Technology Transfer Center (ATTC) Network Coordinating Office. Retrieved from http://attcnetwork.org/ATTC_WhitePaper-final-web.pdf

[5] Annapolis Coalition on the Behavioral Health Workforce. (2015). Competencies. Cincinnati, $\mathrm{OH}$ : Annapolis Coalition on the Behavioral Health Workforce. Retrieved from http://annapoliscoalition.org/?portfolio=competencies

[6] Institute of Medicine (IOM). (2003). Health professions education: A bridge to quality. Washington, DC: The National Academies Press. Retieved from http://www.nap.edu/ openbook.php?record_id=10681\&page $=121-144$

[7] Irajpour, A., \& Alavi, M. (2015). Health professionals' experiences and perceptions of challenges of interprofessional collaboration: Socio-cultural influences of IPC. Iranian Journal of Nursing and Midwifery Research, 20(1), 99-104.

[8] McInnes, S., Peters, K., Bonney, A., \& Halcomb, E. (2015). An integrative review of facilitators and barriers influencing collaboration and teamwork between general practitioners and nurses working in general practice. Journal of Advanced Nursing, 71(9), 1973-1985. doi: $10.1111 /$ jan.12647

[9] Liaw, S. Y., Zhou, W. T., Lau, T. C., Siau, C., \& Chan, S. W. (2014). An interprofessional communication training using simulation to enhance safe care for a deteriorating patient. Nurse Education Today, 34(2), 259-264. doi: 10.1016/j.nedt.2013.02.019

[10] Nandan, M., \& Scott, P. A. (2014). Interprofessional practice and education: Holistic approaches to complex healthcare challenges. Journal of Allied Health, 43(3), 150-156.

[11] Supper, I., Catala, O., Lustman, M., Chemla, C., Bourgueil, Y., \& Letrilliart, L. (2014). Interprofessional collaboration in primary health care: A review of facilitators and barriers perceived by involved actors. Journal of Public Health (Oxford), 37(4), 716-727. doi: 10.1093/pubmed/fdu10

[12] Hanyok, L. A., Walton-Moss, B., Tanner, E., Stewart, R. W., \& Becker, K. (2013). Effects of a graduate-level interprofessional education program on adult nurse practitioner student and internal medicine resident physician attitudes towards interprofessional care. Journal of Interprofessional Care, 27(6), 526-528. doi: 10.3109/13561820.2013.790881

[13] Makino, T., Shinozaki, H., Hayashi, K., Lee, B., Matsui, H., Kururi, N., Watanabe, H. (2013). Attitudes toward interprofessional healthcare teams: A comparison between undergraduate students and alumni. Journal of Interprofessional Care, 27(3), 261-268. doi: $10.3109 / 13561820.2012 .751901$

[14] Owen, J. A., \& Schmitt, M. H. (2013). Integrating interprofessional education into continuing education: A planning process for continuing interprofessional education programs. Journal of Continuing Education in the Health Professions, 33(2), 109-117. doi: 10.1002/chp.21173

[15] Bennett, P. N., Gum, L., Lindeman, I., Lawn, S., McAllister, S., Richards, J., \& Ward, H. (2011). Faculty perceptions of interprofessional education. Nurse Education Today, 31(6), 571-576. doi: 10.1016/j.nedt.2010.09.008

[16] Servis, M. (2010, April). Interprofessional education: Challenges and solutions. Paper presented at the AAMC Western Group on Educational Affairs (WGEA) Annual Conference, Pacific Grove, CA. PowerPoint slides retrieved from http://www.ucdmc.ucdavis.edu/mdprogram/ conferences/images/WGEA-Plenary-3-Servis.ppt

[17] Gaba, D. M. (2004). The future vision of simulation in health care. Quality and Safety in Health Care, 13, I2-I10.

[18] Barnes, L. B., Christensen, C. R., \& Hansen, A. J. (1994). Teaching and the case method: Instructor's guide. Boston, MA: Harvard Business School Press. 
[19] International Nursing Association for Clinical Simulation and Learning (INACSL). (2015). Standards of best practice: Simulation. Morrisville, NC: INACSL. Retrieved from http://www.inacsl.org/i4a/pages/index.cfm?pageid=3407

[20] Ellet, W. (2007). The case study handbook: How to read, discuss, and write persuasively about cases. Boston, MA: Harvard Business Review Press.

[21] Skinner, H. A. (1982). The drug abuse screening test. Addictive Behavior, 7(4), 363-371.

[22] Babor, T. F., Higgins-Biddle, J. C., Saunders, J. B., \& Monteiro, M. G. (2001). The alcohol use disorders identification test: Guidelines for use in primary care (2nd ed.). Geneva: World Health Organization, Department of Mental Health and Substance Dependence.

[23] World Health Organization. (2010). Framework for Action on Interprofessional Education and Collaborative Practice. Geneva, Switzerland: WHO Press.

[24] Measuring the Impact of Interprofessional Education (IPE) on Collaborative Practice and Patient Outcomes - Institute of Medicine. (April, 2015). Retrieved May 6, 2015, from http://www.iom.edu/Reports/2015/Impact-of-IPE

[25] National Center for Interprofessional Practice and Education (NCIPE). (2015). Measurement instruments. Regents of the University of Minnesota. Retrieved from https://nexusipe.org/measurement-instruments

[26] Berwick, D. M., Nolan, T. W., \& Whittington, J. (2008). The Triple Aim: Care, Health, And Cost. Health Affairs, 27(3), 759-769. doi:10.1377/hlthaff.27.3.759

\section{AUTHORS' BIOGRAPHY}

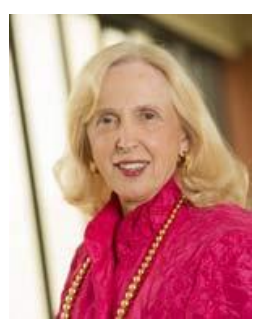

\section{Kathy Puskar, DrPH, RN, FAAN}

Dr. Puskar is currently the PI of a HRSA-funded grant on targeting substance use in rural populations. She was also previously funded through HRSA for a project on Addictions Training for Nurses Using SBIRT. Dr. Puskar has published more than 150 papers in refereed journals, authored book chapters, and gathered several awards for her research. She is the Past President of the American Psychiatric Nurses Association, a Fellow of the American Academy of Nursing, and a Fellow of the National Academies of Practice. Dr. Puskar has served as a reviewer for NIMH grants and is a past member of the University Institutional Review Board (IRB). She is a national consultant to inpatient and outpatient behavioral health programs.

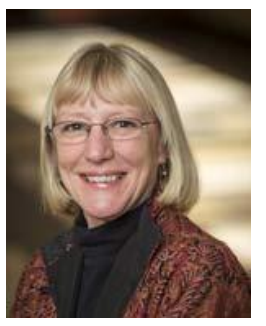

\section{Ann M. Mitchell, PhD, RN, FAAN}

Dr. Mitchell is a professor at the University of Pittsburgh School of Nursing. Dr. Mitchell is currently the Project Director (PI) on two HRSA-funded grants designed to teach Screening, Brief Intervention, and Referral to Treatment (SBIRT) to Emergency Department Registered Nurses (EDRN) and Interprofessional Groups of Anesthesia Students (InGAS). She is also funded by SAMHSA to integrate SBIRT training into the Nurse Practitioner curriculum, addressing substance use across the lifespan.Lastly, she is working with the CDC on two projects to incorporate Alcohol Screening and Brief Intervention (Alcohol SBI) into nursing practice with the ultimate goal of preventing Fetal Alcohol Spectrum Disorders (FASD).

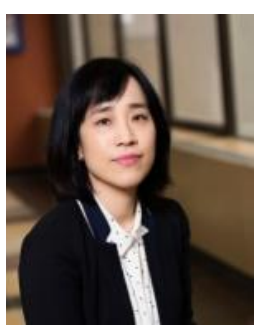

\section{Heeyoung Lee, PhD, PMHNP-BC}

Dr. Lee is an Assistant Professor in the Department of Health and Community Systems at the University of Pittsburgh School of Nursing. Her research involves working with mentally ill patients and their families. Her research mainly focuses on behavioral interventions to improve mental and physical health outcomes in adults with serious mental illnesses. Dr. Lee teaches several couses in the Psychiatric Mental Health Nurse Practitioner Program. She serves on the membership committee of the Asian American/Oacific Islander Nurses Association (AAPINA) and as a member of Sigma Theta Tau Psi Chapter-at-Large. Additionally, Dr. Lee serves on the University of Pittsburgh School of Nursing MSN and DNP councils. She is a DNP representative on the bylaw and policy committee. 


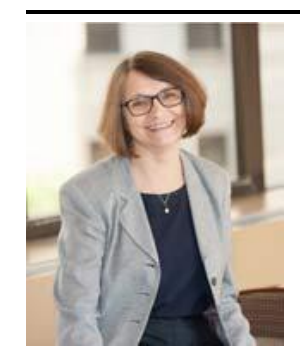

\section{Irene Kane, PhD, MSN, RN, CNAA, EP-C}

Dr. Kane is an Associate Professor of Nursing with extensive clinical, teaching, and research experience in developing and teaching health promotion programs emphasizing disease prevention and health management to improve psychobiological wellbeing. Dr. Kane is a certified Screening Brief Intervention and Referral to Treatment (SBIRT) trainer with over 25 papers published in peerreviewed journals shares her expertise in SBIRT training knowledge, skills and outcomes to address substance use identification with brief interventions earlier along the continuum of use, misuse, abuse and dependence. Lastly, she is working with the CDC to incorporate Alcohol Screening and Brief Intervention (Alcohol SBI) into nursing practice with the ultimate goal of preventing Fetal Alcohol Spectrum Disorders (FASD).

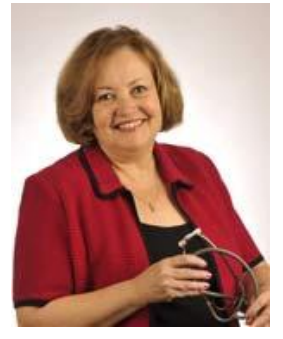

\section{Susan A. Albrecht, PhD, RN, CRNP, FAAN}

Dr. Albrecht is the Associate Dean for Special Projects at the University of Pittsburgh School of Nursing and currently is serving as a Co-Director for the Provost's Innovation Education Award. Her research interests focus on women's health, smoking cessation during pregnancy, relapse prevention, and prevention of initiation of smoking in adolescents and women. Dr. Albrecht has served as Faculty Expert on a study funded by Health Resources and Services Administration (HRSA), Department of Helaht and Human Services on Interprofessional Collaborative Practice Targeting Substance Use in Rural Populations. Additionally, she serves as Maternal-Child Faculty Expert on a study funded by the Centers for Disease Control and Prevention, Prevention of FASDs through National Partnerships.

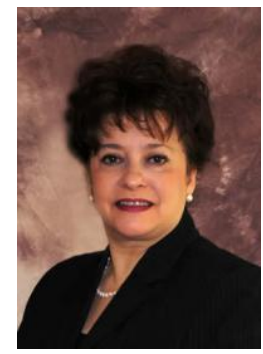

\section{Linda R. Frank, PhD, MSN, ACRN, FAAN}

Dr. Frank is an Associate Professor, Infectious Diseases and Microbiology in the Department of Infectious Diseases at the University of Pittsburgh Graduate School of Public Health. She has been the Principal Investigator (PI) on the Pennsylvania/MidAtlantic AIDS Education and Training Center Project since 1988, and the PI Telehealth AETC Appalachian Project since 2011. Both projects are funded by the Health Resources and Services Administration. Dr. Frank has been recognized by national organizations, universities, and federal agencies for her leadership, expertise, and continued commitment to serving and improving the care for persons with HIV disease and the underserved. Dr. Frank has served and engaged with several boars, legislators, and government officials to improve access to care, reduce disparities, and improve health of individuals and communities.

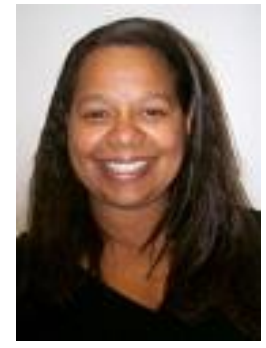

\section{Holly Hagle, PhD}

Dr. Hagle has been actively working with providers since joining the Institute for Research, Education and Training in Addictions (IRETA) in 2003. She is the Director of the National Screening, Brief Intervention and Referral to Treatment Addiction Technology Transfer Center (National SBIRT ATTC) and as such oversees all of the training and educational initiatives. Dr. Hagle oversees the curriculum development and project coordination for three Health Resources and Services Administration (HRSA) SBIRT federally funded projects with the University of Pittsburgh School of Nursing since 2006. Dr. Hagle is an Adjunct Assistant Professor of Health and Community Systems, University of Pittsburgh, School of Nursing. Dr. Hagle has her BS in Psychology, MA in Education, Curriculum and Instruction and $\mathrm{PhD}$ in Education, Instructional Management and Leadership.

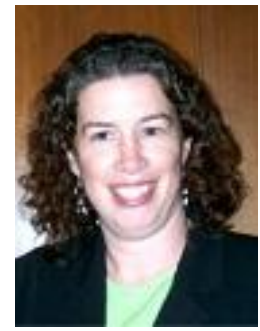

\section{Dawn Lindsay, PhD}

Dr. Lindsay joined IRETA in April 2011. She completed her graduate work in clinical psychology at the University of Cincinnati in 2002 and was on the faculty in the Department of Psychiatry at the University of Pittsburgh until joining IRETA. She has eight years of experience conducting NIDA- and NIAAA-funded 
research in the area of adolescent substance use disorders. She is a member of the American Psychological Association and the American Evaluation Association.

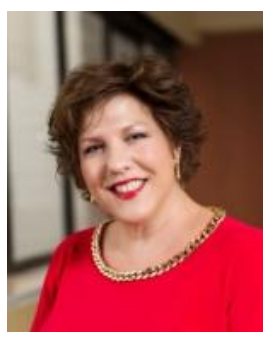

\section{Marie Fioravanti, DNP, RN}

Dr. Fioravanti is an Assistant Professor in the Department of Acute and Tertiary Care at the University of Pittsburgh School of Nursing. She is an expert on evidence-based practice and its implementation, mentoring, and healthcare team effectiveness for making nursing practice changes. Dr. Fioravanti is currently working on three separate Health Resources and Services Administration funded grants designed to teach undergraduate nursing students, advance practice nurses, and emergency department registered nurses the evidence-based practice of Screening, Brief Intervention, and Referral to Treatment (SBIRT) for patients who use alcohol and other drugs. 